\title{
Gas-phase Synthesis of Carbon Nanostructures and Composites
}

\author{
Kh. A. Abdullin ${ }^{1}$, D. G. Batryshev ${ }^{1}$, Y. V. Chikhray ${ }^{2}$, M. T. Gabdullin', \\ D. V. Ismailov ${ }^{1}$, A. K. Togambaeva ${ }^{2}$ \\ ${ }^{1}$ Al-Farabi KazNU, National Nanotechnological Laboratory of Opened Type, al-Farabi Str, Almaty, Kazakhstan \\ ${ }^{2} \mathrm{Al}-$ Farabi KazNU, Institute of Experimental and Theoretical Physics, al-Farabi Str, Almaty, Kazakhstan
}

Received May, 2013

\begin{abstract}
CVD synthesis of carbon nanotubes was carried out using ethanol paralysis in tubular quartz reactor at atmospheric pressure of hydrogen. Ni, Co and Fe catalyst were used for CNT deposition. The CNT samples obtained under various experimental conditions were studied by scanning electron microscopy (SEM), X-ray fluorescent microanalysis and Raman spectroscopy. The ratio of $\mathrm{I}_{\mathrm{D}} / \mathrm{I}_{\mathrm{G}}$ of $\mathrm{D}\left(\sim 1360 \mathrm{~cm}^{-1}\right)$ and $\mathrm{G}\left(\sim 1580 \mathrm{~cm}^{-1}\right)$ Raman peaks was monitored to estimate the crystalline of graphite-like material. The optimal conditions for synthesis of CNTs on the Si-substrates and on the $\mathrm{SiO}_{2}$-based fiberglass were determined. MWNT were produced with 25-30 nm diameters, up to 30 microns in length and with crystallite size $\mathrm{L}_{\mathrm{a}}$ from $2.7 \mathrm{~nm}$ to $7 \mathrm{~nm}$. DC electrical properties of carbon composites $\mathrm{MWNT} / \mathrm{SiO}_{2}$-fiberglass were examined. Specific resistance was about $10 \mathrm{~cm}$ and more depending on CNT content. It was found that the resistivity of the carbon composites $\mathrm{MWNT} / \mathrm{SiO}_{2}$ is sensitive to external pressure. Processing of composite with binding polymer significantly improves stability and repeatability of its voltage-current characteristics.
\end{abstract}

Keywords: Carbon Nanotubes (CNT); Chemical Vapor Deposition (CVD); Scanning Electron Microscopy (SEM); Raman Spectroscopy

\section{Introduction}

Carbon nanotubes (CNT) have found applications in different areas, such as semiconductor structures on unipolar transistors, field emitters, gas sensors, solar cells, catalysts, ultra capacitors etc [1-9]. CNT-based nano-structured composite materials and reinforced polymers have been developed for use in a variety of products. Increasingly wide range of applications of CNT requires a big amount of low cost materials. Therefore, the development of low cost techniques of CNT synthesis still remains actual. In the present work, we fabricate a nanostructure carbon with nickel impurities, carbon nanotubes and carbon-related composites by gas-phase deposition.

\section{Experiment}

The synthesis of CNT by chemical vapor deposition (CVD) was carried out in hydrogen under the atmospheric pressure. The CVD process was carried out in a tube quartz reactor (diameter $25 \mathrm{~mm}$ ) within a tube furnace at temperatures between 600 and $900^{\circ} \mathrm{C}$. Ethanol was used as a carbon source. When the necessary temperature of synthesis was obtained, sweep gas comes via the bubbler filled with ethanol at room temperature.
Single side polished p-type $<111>$ silicon substrates with $\mathrm{SiO}_{2}$ layers and catalyst layer of $\mathrm{Ni}(5 \div 10 \mathrm{~nm}$ thick) were used as a substrate for CNT growth by fixed bed CVD method. Thin nickel films were deposited on Si substrates by electron-beam evaporation of $\mathrm{Ni}$ target.

Silica based glass fiber was also used as a substrate for fixed bed growth of CNT. A catalyst was deposited by wet impregnation method. First of all, $2 \mathrm{~g}$ of nickel nitrate and $2 \mathrm{~g}$ of cobalt nitrate were dissolved into $100 \mathrm{ml}$ distilled water and $10 \mathrm{~g}$ of the silica based glass fiber was immersed in the solution for 24 hours at ambient temperature. Then the solution was poured out and the glass fiber was dried at $100^{\circ} \mathrm{C}$ for $24 \mathrm{~h}$ in an oven. The fibers were loaded in the reactor, filling the entire diameter of the tube quartz reactor. Nitrates were reduced under hydrogen flow while the desired temperature of CNT growth is being achieved.

The Fe was used a catalyst and $\mathrm{TiO}_{2}$ powders with granule size of $\sim 0.2 \mu \mathrm{m}$ was used as a catalyst carrier in the fluidized bed method. The Fe-loaded $\mathrm{TiO}_{2}$ powder was prepared by wet impregnation method during processing of the powder in water solution of iron chloride for 12 hours, with the following drying at $105^{\circ} \mathrm{C}$. The synthesis was carried out in vertical reactor under hydrogen flow. 
The properties of obtained samples were studied by the method of scanning electron microscopy (SEM) with X-ray fluorescence analysis and Raman spectroscopy. Electric characteristics of obtained composites were measured at direct current. The optimal conditions for synthesis of CNT layers were defined.

The Figure 1 shows the morphology of obtained multi-wall CNT with $25-70 \mathrm{~nm}$ in diameter and $\sim 30 \mu \mathrm{m}$ in length. The Figure 2 demonstrates the Raman spectra of obtained CNT samples. As it is well known [10], that the intensity of the D band compared with the Raman- allowed $G$ band depends on the size $\left(L_{a}\right)$ of the graphite micro crystals in the sample, and $\mathrm{L}_{\mathrm{a}}$ can be defined by the Tuinstra-Koenig relationship $\mathrm{L}_{\mathrm{a}}=4.4 \cdot \mathrm{I}(\mathrm{G}) / \mathrm{I}(\mathrm{D}) \mathrm{nm}$ which is used for the estimation of sizes of crystallites. The Raman spectra obtained (Figure 2) demonstrates that the ratio of $\mathrm{I}(\mathrm{G}) / \mathrm{I}(\mathrm{D})$ depends on parameters of synthesis and the sizes of CNT crystallites are varied from $2.4 \mathrm{~nm}$ to $5.2 \mathrm{~nm}$.

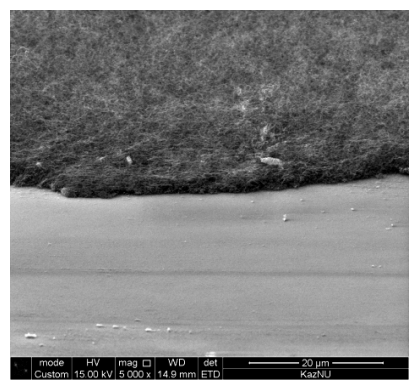

(a)

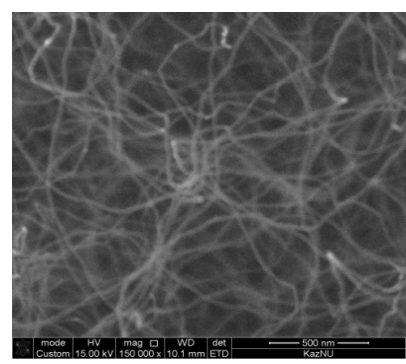

(b)

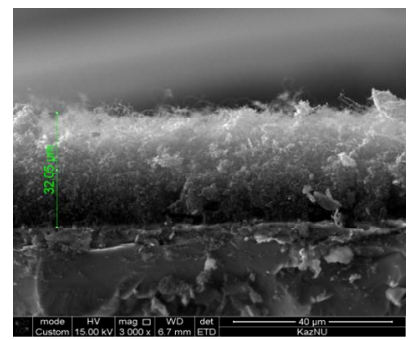

(c)

Figure 1. SEM of CNT layers on silicon substrates. CNTs were obtained at $\sim 800^{\circ} \mathrm{C}$ for $15 \mathrm{~min}$ in hydrogen atmosphere. The magnification of the SEM images is 150000 (a), 5000 (b) and 3000 (c). SEM images of the CNT were obtained at a tilt angle of $0^{\circ}$ (a), $70^{\circ}$ (b) and $90^{\circ}$ (c).

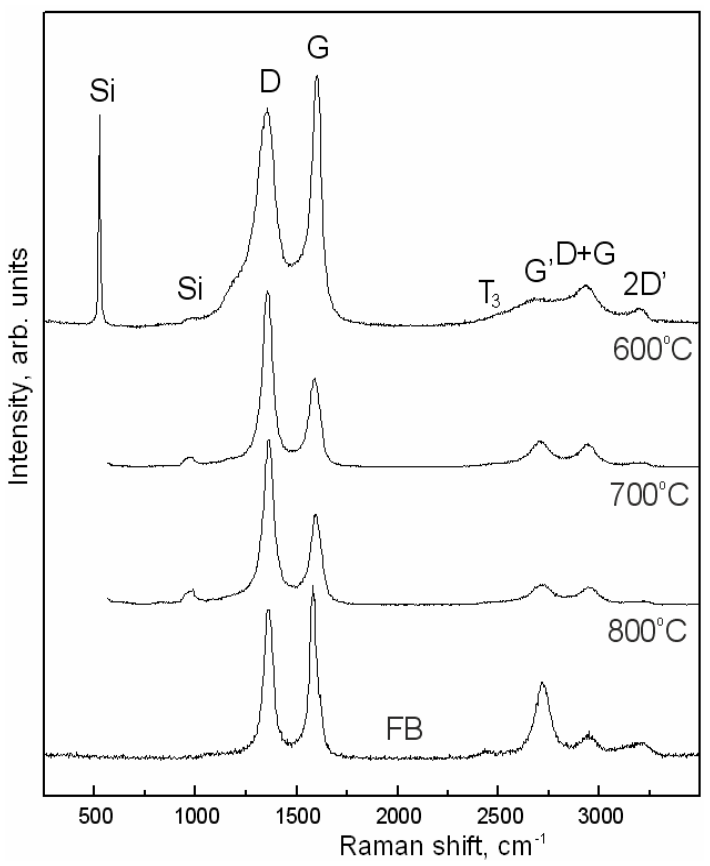

Figure 2. Raman spectra of CNT layers obtained on $\mathrm{Si}+\mathrm{Ni}$ substrates at growth temperatures of 600,700 and $800^{\circ} \mathrm{C}$, and Raman spectra of CNTs on $\mathrm{TiO}_{2}$ powder with Fe catalyst. The Raman spectra were obtained in a NTEGRA Spectra spectrometer (NT-MDT) equipped with a $473 \mathrm{~nm}$ excitation laser.

The SEM studies have shown that annealing of silicon substrates with catalytic nickel layer at temperatures $650-900^{\circ} \mathrm{C}$ in the inert or hydrogen atmosphere without supplying of carbon containing components leads to the formation of nickel nanoclusters at the surface of silicon oxide. The average size of nanoclusters ranges from 5 to $50 \mathrm{~nm}$ and depends on the thickness of deposited $\mathrm{Ni}$ layer. These nanoclusters are acting as catalysts of CNT growth by widely-accepted CNT growth mechanism, which assumes that the hydrocarbon vapor is adsorbed to the metal nanoparticles upon reaching supersaturating and then carbon atoms precipitate out in the form of CNTs.

The $\mathrm{SiO}_{2}$ based fibers were used as catalyst carriers to increase the amount of CNT grown in a single experiment. The morphology of obtained samples is shown on Figure 3. As it can be seen from this figure, the $\mathrm{SiO}_{2}$ fibers are covered more or less uniformly by CNTs which are $20-80 \mathrm{~nm}$ in diameter. Raman scattering spectra have shown that the CNTs deposited on fibers have lower crystalline than those obtained on Si-Ni substrates.

The Figure 4 shows the morphology of CNTs obtained in vertical fluidized bed reactor with use of $\mathrm{Fe}$ catalyst loaded on $\mathrm{TiO}_{2}$ particles. It can be concluded from the Raman spectra (Figure 2) that the level of crystallinity of CNTs obtained in fluidized bed is quite high, the estimated size of crystallites is about $5 \mathrm{~nm}$. 


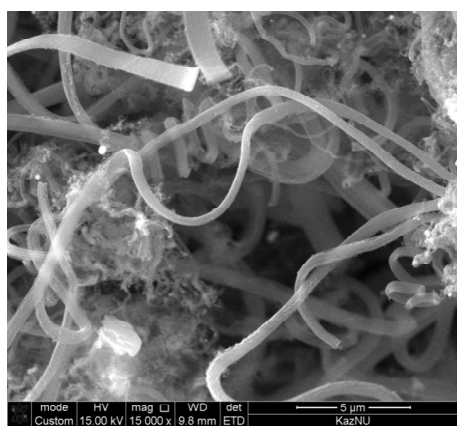

(a)

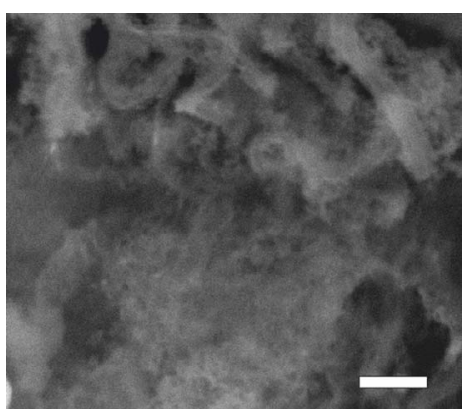

(b)

Figure 3. SEM images of CNT layers deposited in hydrogen atmosphere on $\mathrm{SiO}_{2}$ fibers with $\mathrm{Ni}-\mathrm{Co}$ catalyst at temperature of $700{ }^{\circ} \mathrm{C}$. The magnification of the SEM images is 15000 (a) and 100000 (b). The bar in the right-lower corner in frame $b$ is shown as scale of $500 \mathbf{~ n m}$.

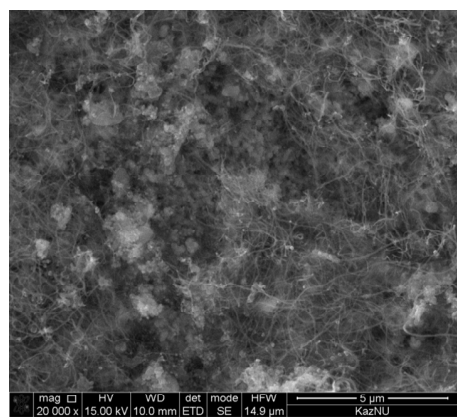

(a)

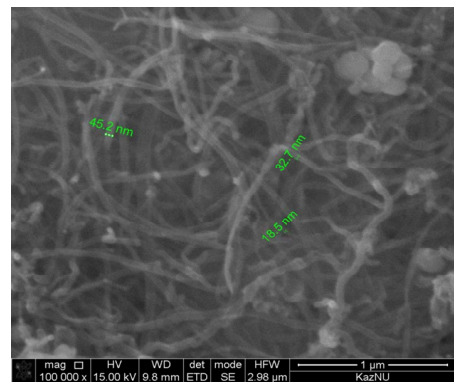

(b)

Figure 4. SEM images of CNT layers deposited on $\mathrm{TiO}_{2}$ powder with Fe catalyst. CNTs were obtained on fluidized bed catalyst in hydrogen atmosphere at $\mathrm{TiO}_{2}$ powder with iron catalyst at temperature of $800^{\circ} \mathrm{C}$, after 60 minutes of synthesis, zoom: 100000 (a) and 20000 (b).

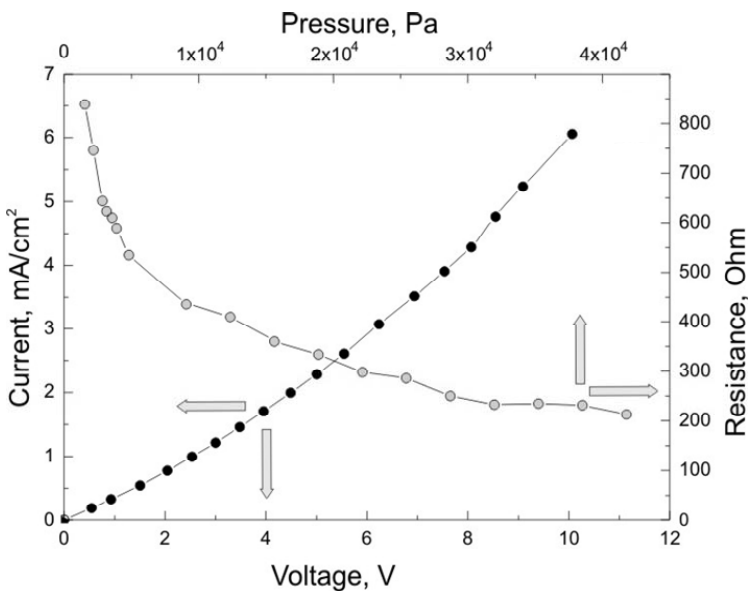

(a)

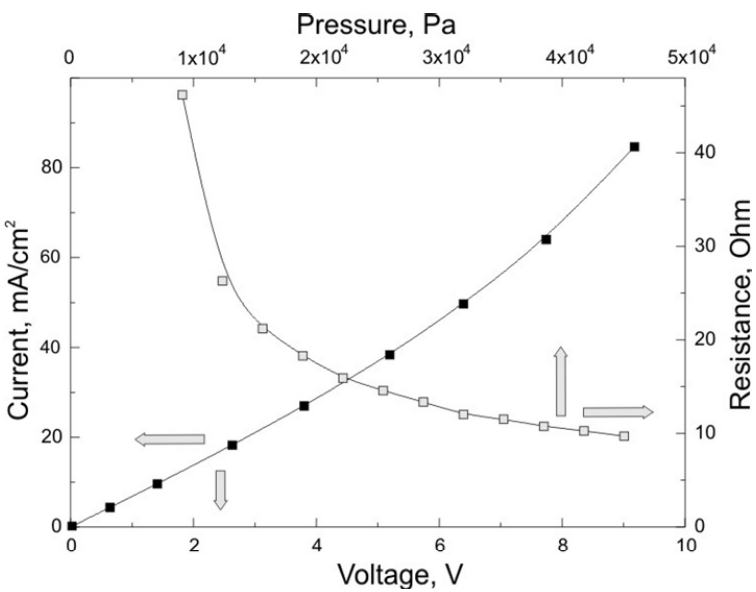

(b)

Figure 5. Volt-ampere curves and dependence of electrical conductance from the external pressure for two types of composites: a- with low content of CNT and b - with high content of CNT.

The composite material of $\mathrm{SiO}_{2}$ fibers covered with multi-walled CNTs has a high electrical conductance. Room temperature direct current (DC) electrical conductance was measured for these composites. It was found that resistivity of the composites can be easily varied in the range from $10 \mathrm{ohm}^{*} \mathrm{~cm}$ and higher. The resistivity of the composite depends on synthesis conditions and content of CNTs in the composite. Voltage-current characteristics were found to be close to the linear dependences and have shown at Figure 5 for two samples with low (a) and high (b) CNT content. It was find out that the electric conductance of composites is quite sensitive to the external pressure.

Electrical resistance of the composite under various external pressure in the range of $0.03 \sim 0.15 \mathrm{MPa}$, and when it under the fixed voltage $(5 \mathrm{~V})$ decreases rapidly as the pressure increases. The samples with different electrical conductance have different pressure sensitivity. The stability of electrical properties and pressure sensi- 
tivity of composites is considerably increased by reinforcement of the CNT composite structure by impregnation with binding polymer.

\section{Acknowledgements}

The work was carried out under the support of Ministry of Education of Kazakhstan, grants GF 1106 and GF 1109.

\section{REFERENCES}

[1] A. V. Eletskii, “Carbon Nanotubes,” UFN 167, 1997, pp. 945-972. doi:10.3367/UFNr.0167.199709b.0945

[2] R. Saito, G. Dresselhaus, et al., "Physical Properties of Carbon Nanotubes,” Singapore, World Scientific Publishing Co. Pte. Ltd, 1998.

[3] F. F. Komarov and A. M. Mironov, "Carbon Nanotubes: Present and Future,” Physics and Chemistry of Solid State, Vol. 5, No. 3, 2004, pp. 411-429.

[4] M. S. Dresselhaus, G. Dresselhaus, J. C. Charlier and E. Hernandez, "Electronic, Thermal and Mechanical Proper- ties of Carbon Nanotubes," Philosophical Transactions of the Royal Society A, Vol. 362, 2004, pp. 2065-2098. doi:10.1098/rsta.2004.1430

[5] P. N. Diachkov, "Carbon Nanotubes," The Structure, Properties and Applications, Persistence, Laboratory of Knowledge, 2006, p. 296.

[6] H. Qian, E. S. Greenhalgh, M. S. P. Shaffer and A. Bismarck, "Carbon Nanotube-based Hierarchical Composites: a Review," Journal of Materials Chemistry, Vol. 20, 2010, pp. 4751-4762. doi:10.1039/c000041h

[7] Y. Wang and J. T. W. Yeow, "A Review of Carbon Nanotubes-Based Gas Sensors,” Journal of Sensors 2009, 2009, pp. 1-24, doi:10.1155/2009/493904

[8] M. Kumar and Y. Ando, "Chemical Vapor Deposition of Carbon Nanotubes: A Review on Growth Mechanism and Mass Production," Journal of Nanoscience and Nanotechnology Vol. 10, 2010, pp. 3739-3758. doi:10.1166/jnn.2010.2939

[9] F. Tuinstra and J. L. Koening, "Raman Spectrum of Graphite,” Journal of Chemical Physics, Vol. 53, No. 3, 1970, p. 1126. $\underline{\text { doi:10.1063/1.1674108 }}$ 